\title{
Behavior of NiTi Wires for Dampers and Actuators in Extreme Conditions
}

A. Isalgue $1, *$

Email antonio.isalgue@upc.edu

C. Auguet 1

Email carlota.auguet@upc.edu

R. Grau 1

V. Torra 1

N. Cinca 12

Emailncinca@cptub.eu

\section{J. Fernandez 2}

Email javier.fernandez@ub.edu

1 Dep. Física Aplicada and CEN, Universitat Politècnica Catalunya, Pla Palau, 18, 08003 Barcelona, Spain

2 CPT- Dep. CMEM, Facultat Química Universitat Barcelona, Diagonal 645, 08028 Barcelona, Spain

\section{Abstract}

Shape memory alloys are considered smart materials because of their singular thermo-mechanical properties, due to a thermoelastic martensitic transformation, enabling possible uses as actuators (because of mechanical recovery induced from temperature changes) and as dampers (because of hysteresis). NiTi wires for dampers in Civil Engineering had been characterized and tested in facilities. Guaranteed performance needs to know behavior during fatigue life and knowledge of effects in the event of extreme conditions, as eventual overstraining. In this work, we check the possibilities to absorb mechanical energy on the fatigue life depending on stress level and explore the consequences of overstraining the material 
during installation, the possibilities of partial healing by moderate heating, and some effects of over-stressing the wires. The mechanical energy absorbed by the unit weight of damper wire might be very high during its lifetime if maximum stresses remain relatively low allowing high fatigue life. We show also some results on NiTi wire working as an actuator. The lifetime mechanical work performed by an actuator wire can be very high if applied stresses are limited. The overstraining produces relevant "residual" deformation, which can be to some extent reversed by moderate heating at zero stress. The reason for the observed characteristics seems to be that when external high stresses are applied to an NiTi wire, it undergoes some plastic deformation, leaving a distribution of internal stresses that alter the shape and position of the macroscopic stress-strain transformation path.

\section{Keywords}

creep and stress rupture

failure analysis

intermetallics

mechanical

NiTi

shape memory alloys

thermo-mechanical processing

A portion of this article was presented at the International Conference on Shape Memory and Superelastic Technologies 2013, held May 20-24, 2013, in Prague, Czech Republic.

\section{Introduction}

Shape memory alloys are considered smart materials because of their singular thermo-mechanical properties, due to a thermoelastic martensitic transformation between metastable phases, enabling possible uses as actuators (because of mechanical strain recovery induced from temperature changes) and as dampers (because of hysteresis on the mechanical transformation) (Ref 1 ). Many applications of SMA need a controlled reproducibility and a careful evaluation of the fatigue life under thermal and mechanical actions (Ref 2).

Among the applications of SMA, NiTi wires for dampers in Civil Engineering have been characterized and tested in facilities, where they showed good performance in damping of cables, enabling a reduction of the steady 
oscillation amplitude to $50 \%$, and a considerable shortening of the time to decrease the oscillation after a force impulse (Ref 3-5). The reliable performance of SMA dampers needs a known life time in terms of fatigue, both structural and functional (Ref 6). The increase in fatigue life might be obtained by a reduction of working stresses (and strains). In these conditions, damping is reduced as energy absorbed per mechanical cycle is lower. However, life performance might imply a larger amount of vibration energy absorbed due to the higher number of cycles possible. The effects of maintaining the NiTi alloy at different temperatures near room temperature have been previously investigated (Ref 7,8). Temperature effects on cycling have been characterized, aiming at damping applications (Ref 9), and the effects of size or wire diameter and frequency of cycling on damping behavior have been also characterized (Ref 10$)$.

In this work, we explore the changes in stress-strain cycle shape for the damper (pseudoelastic NiTi) wire, the hysteresis energy, the total mechanical energy absorbed during the lifetime, the consequences of overstraining the material, for instance during installation, and the possibilities of partial healing by moderate heating. We show also some results on NiTi wire working as an actuator (martensitic at room temperature). There is some performance as an actuator at high stresses, with limited strain recovery, high non-recoverable strain, shorter fatigue life to fracture, and reduced total work (in the life time) that can be obtained from the actuator.

\section{Experimental}

Three kinds of NiTi wires have been studied: First one, pseudoelastic wires of $2.46 \mathrm{~mm}$ diameter (from Special Metals - actually Memry corp., a division of SAES Getters, Italy), with composition of 55.95 wt.\% $\mathrm{Ni}$ and balance in $\mathrm{Ti}$, intended for use as dampers in civil engineering. The tensile forces to mechanically transform the wires are in the $3 \mathrm{kN}$ traction range at room temperature.

Second one is the thinner pseudoelastic wires, $0.5 \mathrm{~mm}$ diameter (from Special Metals - actually Memry corp., a division of SAES Getters, Italy), with forces to mechanically transform the wire in the $100 \mathrm{~N}$ traction range at room temperature. For this wire and the previous one, the furnisher indicates that the nominal composition was Ni 55.95 and 55.92 wt.\% with balance in Ti, and the nominal transformation temperatures (As, austenite start) were similar, 243 and $248 / 247 \mathrm{~K}$. 
Third one is a $0.6-\mathrm{mm}$-diameter wire from AMT, in martensitic state at room temperature, intended for use as an actuator, with temperature to stress-free retransform the wire to austenite state of $325 \mathrm{~K}$ (as measured by DSC).

The pseudoelastic NiTi wires of $2.46 \mathrm{~mm}$ diameter were tested for fatigue, cycled in MTS hydraulic testing machine in strain control, at frequencies up to $4 \mathrm{~Hz}$. The mechanically cycled samples in fatigue tests had previously performed a "training" of 100 cycles to $8 \%$ strain, at $100 \mathrm{~s}$ per cycle, to stabilize the behavior, as the first cycles show strong evolution on the shape of force-displacement (or stress-strain) graph with the number of cycle.

The pseudoelastic NiTi wire of $0.5 \mathrm{~mm}$ diameter was cycled with a home-made straining machine, computer controlled, enabling a DC current on the sample (to heat the sample when needed), permitting more than 100-cm-long samples. The stepper motor and the mechanics used allowed only slow cycles $(600 \mathrm{~s}$ per cycle and lower speed were possible). The wire was checked for overstraining effects.

The 0.6-mm-diameter wire was thermally cycled at constant stress and low speed (suspended weight) by a home-made device controlled with a computer, switching DC current through the wire (heating the wire up to $120^{\circ} \mathrm{C}$ over room temperature), with a 100 -s period (50 s on and $50 \mathrm{~s}$ off), and measuring voltage across the wire to detect the failure.

\section{Results and Discussion}

The mechanical cycles presented an "S-shaped" appearance for the 2.46-mmdiameter wire after the "training" procedure. The "residual" or "permanent" deformation ("creep") situated near 1.6-1.9\% from the initial dimension. The specific energy absorbed by the wire, defined as mechanical work absorbed on cycling, or the integral of force by increment of displacement for a complete cycle, per unit mass of wire, decreased on cycling during the "training" to stabilize the properties, similarly to the increase of the "residual" accumulated strain, showing both an approach to a stable state in a little more than 20 cycles (see Fig. 1). We used 100 cycles of "training" for the pseudoelastic wire for dampers.

\section{Fig. 1}

Left: Cycles 1 and 100 on the "training" of pseudoelastic NiTi wire $(2.46 \mathrm{~mm}$ diameter). Right: Specific energy absorbed per cycle (in $\mathrm{J} / \mathrm{kg}$ ) and accumulated 
residual (permanent) strain for NiTi wire of $2.46 \mathrm{~mm}$ diameter, 100 cycles to $8 \%$ strain at $100 \mathrm{~s}$ per cycle ("training" or stabilization of properties procedure)
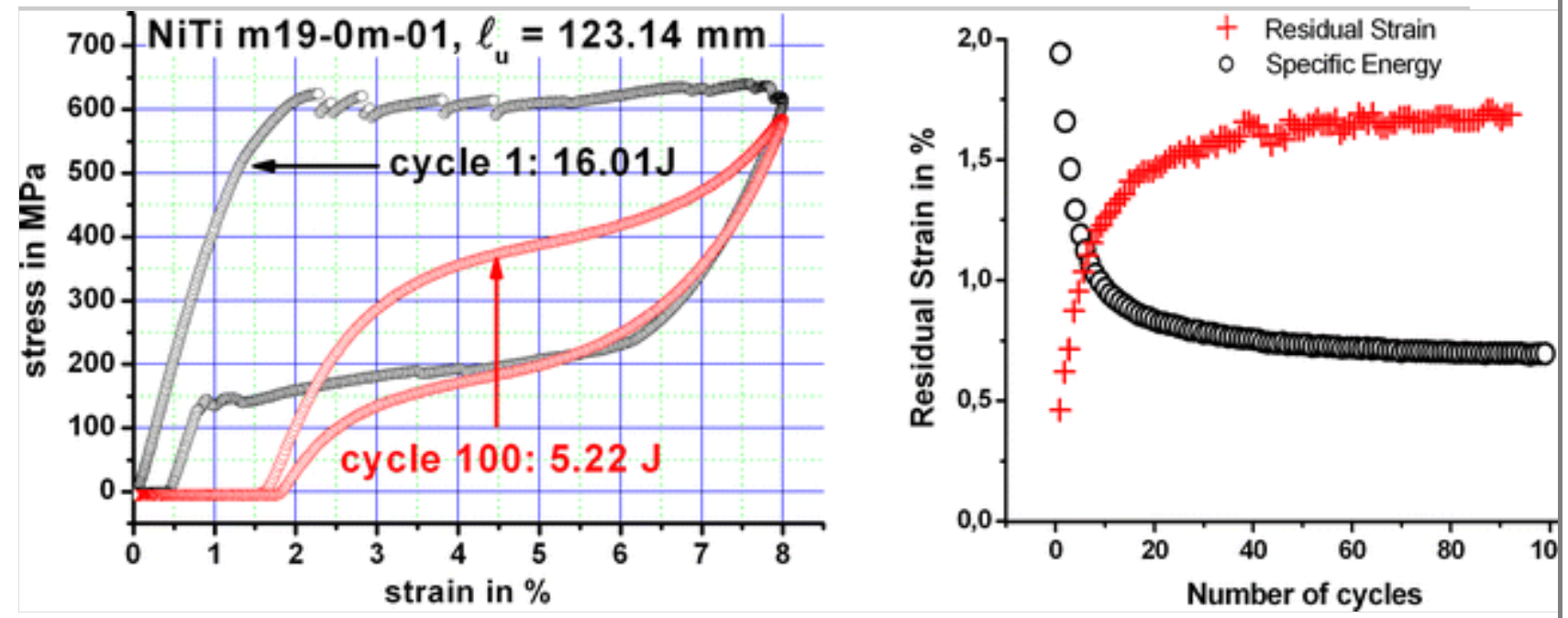

\section{Structural Fatigue and Dissipated Energy in Damper}

In the references, data can be found concerning mechanical fatigue of NiTi with relative high dispersion (Ref 11-15). The initial state of the material influences strongly fatigue performance, and SMAs are in general very sensitive to previous thermo-mechanical treatments. Fatigue failure comes many times from a surface defect inducing crack growth, and this means that fatigue has to be studied for concrete applications, with the correct samples, as the state of the material might present size effects on fatigue (Ref 16). Frequency effects are also relevant for functional fatigue (Ref 10). The maximum stress appears to be the representative variable to describe the life to fracture (Ref 2). The results show that the Basquin law (Ref 17, 18) gives a practical approach to the fatigue life for the 2.46-mm-diameter wire. For this wire, the relationship of the number of cycles to failure $\mathrm{Nf}$ to maximum applied stress could be approached as follows: maximum stress (in $\mathrm{MPa})=170+\mathrm{Nf}^{-0.4}(\operatorname{Ref} 2)$.

For the 2.46-mm-diameter wire with S-shaped, stabilized stress-strain cycles at room temperature, the energy dissipated per mechanical cycle starts to be appreciable at near $0.8 \%$ maximum strain from the residual strain, with some $16 \mathrm{~J} / \mathrm{kg}$ of absorbed energy per cycle on NiTi wire. The energy dissipated per cycle evolves in a near parabolic form by increasing the strain. At $2.25 \%$ maximum strain, the energy per cycle amounts to $115 \mathrm{~J} / \mathrm{kg}$, and at maximum strain to fully transform, the energy dissipated per cycle reaches near $1.4 \mathrm{~kJ} / \mathrm{kg}$. It has to be noted that the initial cycle had larger absorbed energy, near $4 \mathrm{~kJ} / \mathrm{kg}$, but the value changes strongly during the first cycles, making it 
difficult to apply for a reliable design if many cycles have to be done.

It has to be noted that a damper wire (NiTi wire of $2.46 \mathrm{~mm}$ diameter), working at $0.8 \%$ maximum strain (stress under $200 \mathrm{MPa}$ ), has a fatigue life (to fracture) in the $4 \times 10^{6}$ cycles range (Ref 2), so $64 \mathrm{MJ} / \mathrm{kg}$ of mechanical work (vibration energy) can be absorbed in the lifetime. However, if the wire is made to work in the $2.25 \%$ maximum strain, life would be some 40,000 cycles (Ref 2), and absorbed energy in the lifetime results as $4.6 \mathrm{MJ} / \mathrm{kg}$. In the $8 \%$ strain regime, the average work absorbed per cycle will be some $1400 \mathrm{~J} / \mathrm{kg}$, but the life extends to some 2000 cycles (Ref 2), and the total work absorbed would be $2.8 \mathrm{MJ} / \mathrm{kg}$.

AQ1

\section{Functional Fatigue of Actuator}

The 0.6-mm-diameter wire was thermally cycled at constant load, at low frequency $(0.01 \mathrm{~Hz})$, heating it by an electric current. The thermally cycled wires accumulated residual ("permanent") deformation, especially during the first 20 cycles (Fig. 2). The residual deformation was some $4.5 \%$ at $528 \mathrm{MPa}$ in traction, and the actuator could recover $2.3 \%$ strain by heating. The residual deformation was more than $5 \%$ at high stresses (near $800 \mathrm{MPa}$ ), with recovery of near $1.5 \%$ strain (Fig. 3 ). At very low stresses, the phase change is not mechanically driven to full transformation, so recovery strain increases by increasing stress (see Fig. 3 left, up to 100-150 MPa). At higher stresses, plastic strain starts to develop and recovery strain does not increase more than some 4\%, see Fig. 3 left, stresses from 150 to $350 \mathrm{MPa}$. At still higher stresses, the plasticity starts to dominate and recovery goes down (Fig. 3 left, above $350 \mathrm{MPa}$ ).

Fig. 2

Strain for $0.6-\mathrm{mm}$-diameter NiTi wire thermally cycled at a constant traction stress of $528 \mathrm{MPa}$ 


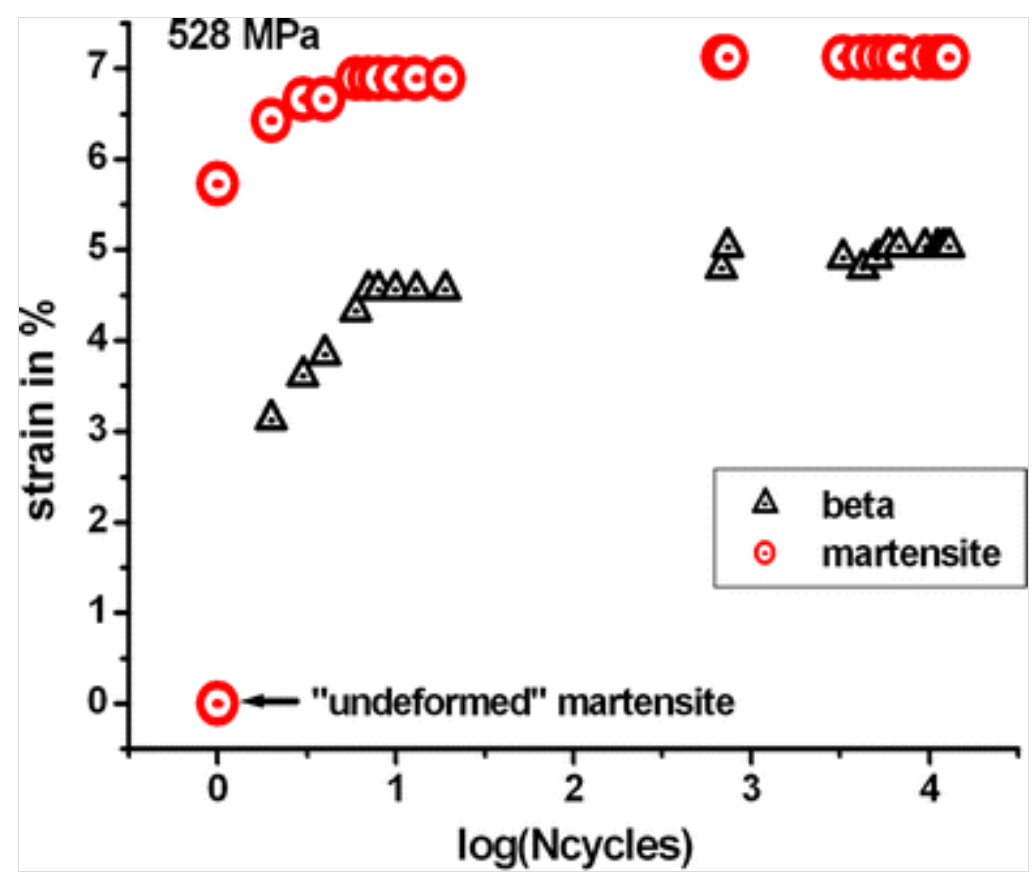

Fig. 3

Left, recovered strain on cycling, after the first cycles, for NiTi wire of $0.6 \mathrm{~mm}$ diameter, as a function of constant applied stress. Right, energy (work) per cycle as a function of constant applied stress, for NiTi wire of $0.6 \mathrm{~mm}$ diameter
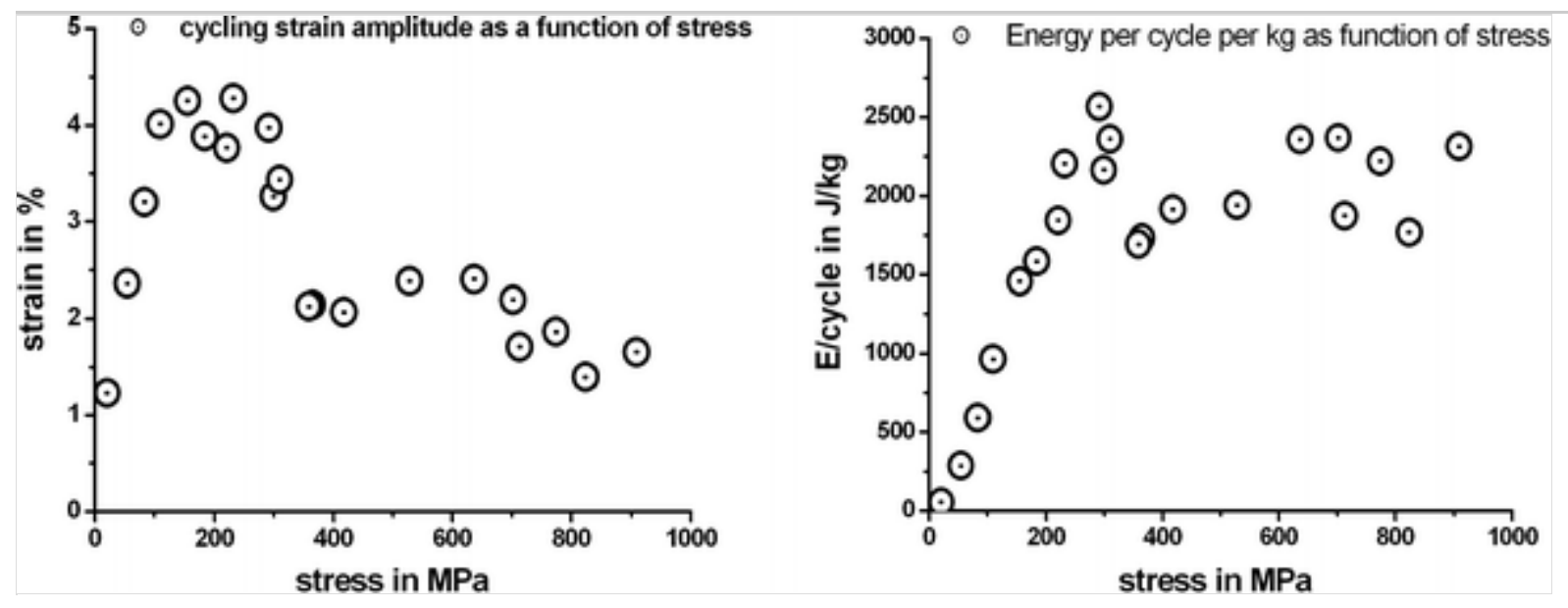

AQ2

The strong initial evolution of the residual (permanent) strain produces that the wire has to be "trained" by more than some 20 initial cycles to be used later as an actuator with reduced changes during the lifetime, a similar effect that the one found by mechanically cycling the pseudoelastic wire.

The actuator wires had some performance at high applied stress; they were able to partially recover shape. However, an increased residual strain develops, higher with higher stress. This makes the wires more difficult to use, as recovery strain might be lower than residual deformation induced by stress. 
Around $1.3 \%$ of strain could be recovered by heating wires at high stresses (near $800 \mathrm{MPa}$ ), with relatively short fatigue life (fracture in less than 2000 cycles). In this case, the residual strain was as high as more than $5 \%$ after 20 cycles.

The mechanical energy (work) the actuator can give on a retransformation cycle (by heating) increases from zero to near $250 \mathrm{MPa}$ of applied stress, giving some $2.5 \mathrm{~kJ} / \mathrm{kg}$. Then, plasticity effects produce a near-constant specific energy the actuator can give per cycle, up to the higher stresses, around $2 \mathrm{~kJ} / \mathrm{kg}$, as the stress increases produce more irrecoverable (plastic) strain.

Also, it has to be noted that an actuator wire (NiTi wire of $0.6 \mathrm{~mm}$ diameter), working at $500 \mathrm{MPa}$, can perform some $2000 \mathrm{~J} / \mathrm{kg}$ of mechanical work per cycle (see Fig. 3 right), and its fatigue life is in the $10^{4}$ cycles to fracture, so some $20 \mathrm{MJ} / \mathrm{kg}$ of work can be obtained. However, if the wire is made to work in the slightly less than $100 \mathrm{MPa}$ stress, the work per cycle will be much lower, some $600 \mathrm{~J} / \mathrm{kg}$ (see Fig. 3 right), but the life extends to more than 40,0000 cycles, and the total work would be much higher, more than $240 \mathrm{MJ} / \mathrm{kg}$.

Then, the wires could be used for damping with large number of working cycles, or for actuators, if the applied stresses are limited to under 100-200 MPa. In this case, the absorbed energy per cycle in damping, or the actuator energy (work) per cycle, is much smaller than in a few cycles of action, but the accumulated energy, taking into account the number of cycles, can be much higher than at larger stresses and strains. The mechanical energy absorbed by the unit weight of wire (or the work done by the actuator wire) might be very high during its lifetime if maximum stresses remain relatively low allowing high fatigue life.

\section{Overstraining Effects and Recovery}

We have also studied the stress-strain behavior after an overstraining of an NiTi pseudoelastic wire. Preliminary observations with the 2.46-mm-diameter NiTi wire showed that the "trained" pseudoelastic wires (that had been cycled 100 times at $0.01 \mathrm{~Hz}$ at room temperature) could recover around half of the residual deformation appeared on cycling at room temperature by heating to $100{ }^{\circ} \mathrm{C}$ at zero stress. Some specific observations were later done. Figure 4 indicates the stress-strain trajectory for non-trained, 0.5-mm-diameter 
pseudoelastic NiTi wire. These wires were able to withstand one-time strains around 15\% and maximum stresses near $1300 \mathrm{MPa}(\operatorname{Ref} 5)$.

Fig. 4

Stress-strain trajectories at room temperature for 0.5 -mm-diameter wire showing the effect of overstraining on the functional performance as a damper. Left, original cycle (full circles) and overstraining to $12 \%$ (up triangles). Right, original cycle (full circles) compared to cycle after overstraining (down triangles)
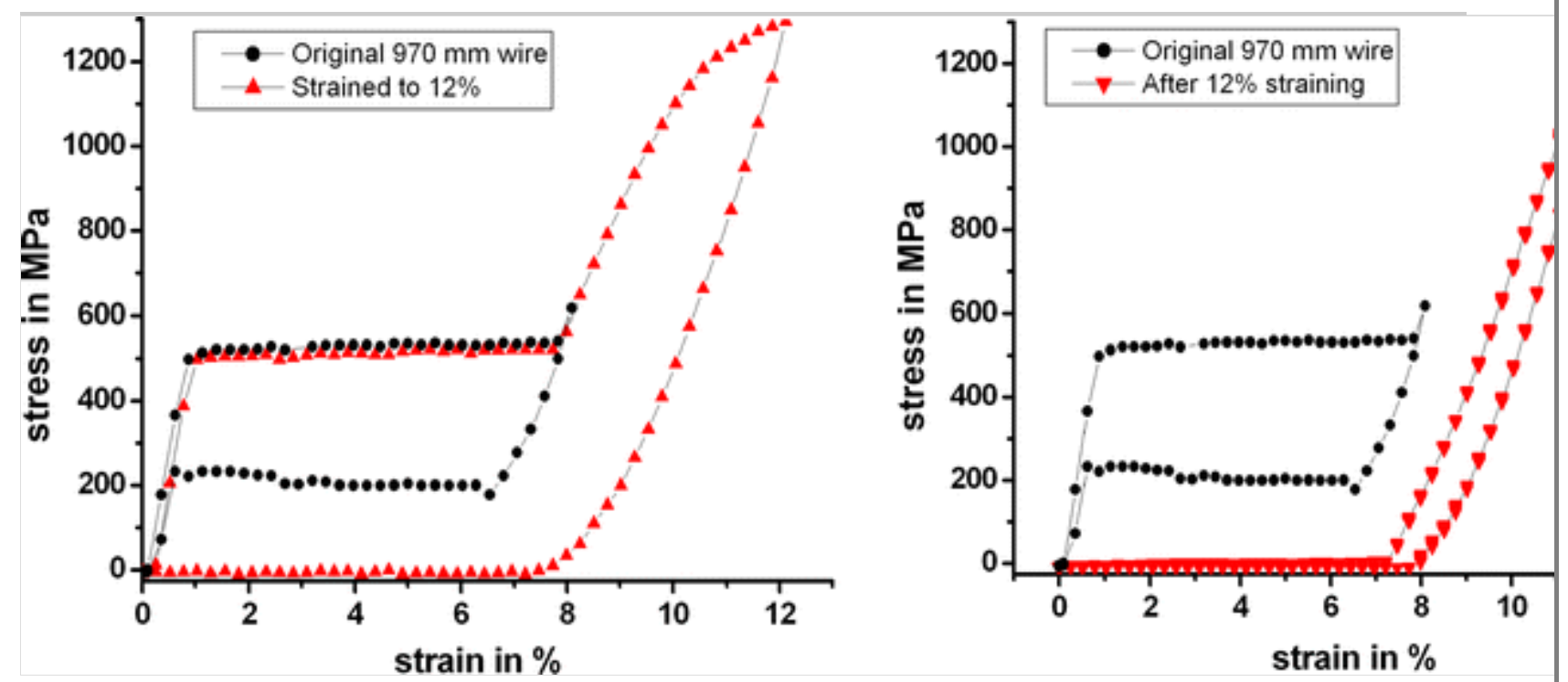

The initial cycle in Fig. 4 left showed an absorbed mechanical energy of $3.6 \mathrm{~kJ} / \mathrm{kg}$ per cycle at $8 \%$ maximum strain. If the wire is strained to $12 \%$, the area of the first straining cycle increases strongly (Fig. 4, left), but recovery force ceases at around 6.5\% strain (residual strain). A later cycle (Fig. 4, right) shows a very different appearance in stress-strain coordinates as referred to the initial cycle, but the new cycle is still able to absorb near $1.9 \mathrm{~kJ} / \mathrm{kg}$ per cycle, if it is strained to $12 \%$ from the initial starting situation (Ref 19).

This shows that, on the one hand, even with a strong change on properties, the wire has still some of its functional performance as a damper. For instance, it might be able to absorb about one half of the mechanical energy per cycle it was designed to absorb at $8 \%$ maximum strain, if it is strained to $12 \%$ maximum strain. On the other hand, it will not be able to re-center a structure or absorb energy at lower deformations after an overstraining, because of the high residual strain.

Further on, if the wire is heated to $100{ }^{\circ} \mathrm{C}$ with zero load, it recovers partly 
from the previous overstrain. The resulting mechanical cycle at room temperature (empty squares), compared with the initial cycle (full circles) and the cycle performed after straining to $12 \%$ (down triangles), is shown in Fig. 5. The healing after heating to $100{ }^{\circ} \mathrm{C}$ is partial, a residual deformation of more than $1 \%$ exists, and the cycle after the heating has lower stresses (both transformation and retransformation plateaus) than the initial cycle, and also a larger residual strain develops during the cycling.

\section{Fig. 5}

Partial recovery (healing) of NiTi wire after heating to $100{ }^{\circ} \mathrm{C}$. Full circles, original (as furnished) wire. Inverted triangles, cycle after overstraining to $12 \%$. Empty squares, cycle after heating the wire to $100{ }^{\circ} \mathrm{C}$

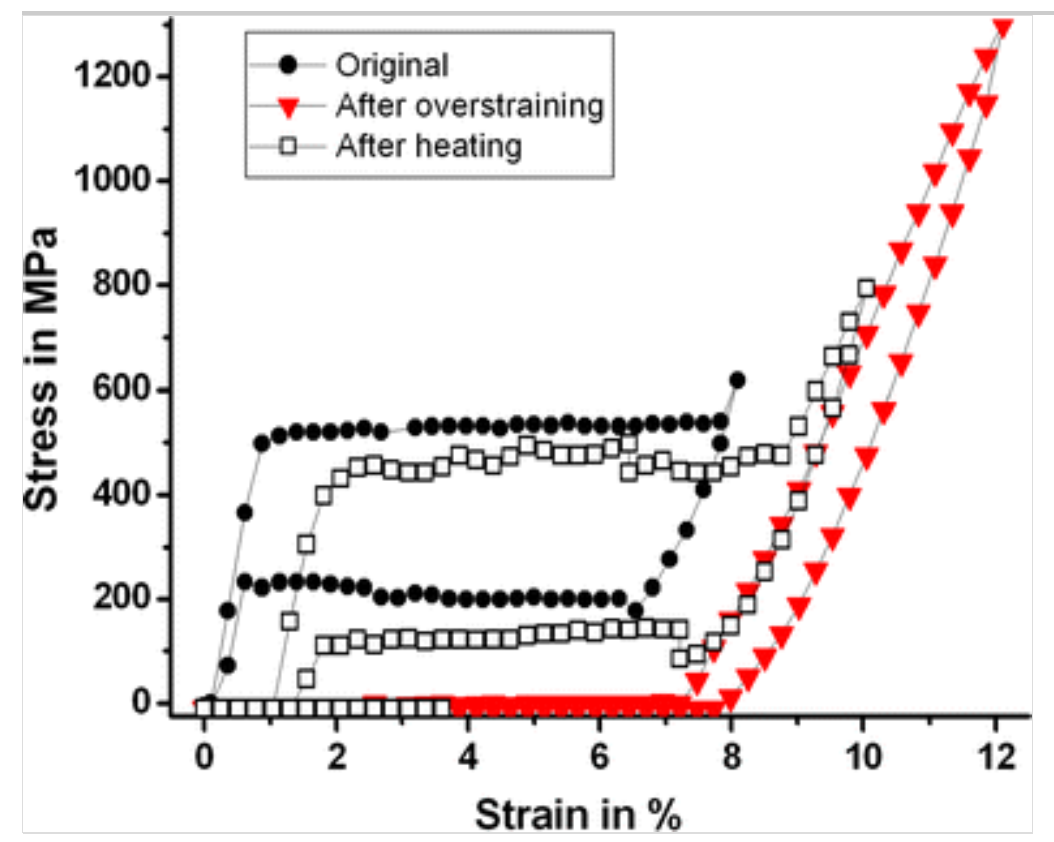

The reason for the observed characteristics seems to be that when high external stresses are applied to a pseudoelastic NiTi wire, it undergoes some plastic deformation, producing a non-uniform distribution of internal stresses that alter the shape and position of the macroscopic stress-strain transformation path and leaves some martensite at room temperature, part of this martensite with relatively low stresses (the high macroscopic stress is to a certain extent supported by other parts of the material, with higherthan-average stresses). Then, the wire might recover some length (partial shape memory effect) by moderate heating, as the part of martensite with lower stresses retransforms to parent phase, redistributing internal stresses and giving some change in macroscopic strain.

\section{Conclusions}


NiTi wires (2.46 mm diameter) could be used for damping in civil engineering. A large number of working cycles can be supported, if the applied stresses are limited to under 100-200 MPa, with reduced performance per cycle (some $16 \mathrm{~J} / \mathrm{kg} /$ cycle of mechanical energy transformed to thermal energy), but with large life performance and a larger amount of total energy (work) absorbed, up to $64 \mathrm{MJ} / \mathrm{kg}$, compared with the use of higher stresses (in the magnitude of $5 \mathrm{MJ} / \mathrm{kg})$. Thin NiTi wires (0.6 mm diameter) could also be used for actuators, with long life and larger total mechanical work output during lifetime if maximum stresses are restricted to around $100 \mathrm{MPa}$.

An overstraining of the wires changes strongly the behavior in stress-strain; the wires conserve some possibility to absorb mechanical energy, but a residual deformation develops and fatigue life (to fracture) is shortened. Then, for application as a damper in civil engineering, it is necessary to adapt the length of the wires to the maximum expected deformation with relatively reduced stress, taking into account design life, or the performance will be strongly reduced with respect to the total energy absorbed by the NiTi wires in the lifetime.

The NiTi actuator wires ( $0.6 \mathrm{~mm}$ diameter) could recover shape partially under high stresses, even with moderate temperature increases $(1.4 \%$ recovery with stresses near $800 \mathrm{MPa}$ ), but in this case large residual deformation appears (higher than $3 \%$ in 20 cycles) and fatigue life (to fracture) is shortened, making it difficult to profit the partial shape recovery.

The results indicate that when high external stresses are applied to an NiTi wire, it undergoes some plastic deformation, leaving non-uniform internal stresses that alter the shape and position of the macroscopic stress-strain transformation path. Then, the wire might recover some length (partial shape memory effect) by moderate heating even at high stresses, because part of the martensite would be at reduced stresses, and temperature could produce some partial retransformation. The change of the hysteresis cycle induced by the high stresses applied justifies the observed performance. The partial healing observed by heating the wire with residual deformation by cycling or by overstraining should be due to retransformation of the martensite part at reduced stresses, producing a re-distribution of internal stresses and a reduction of residual strain.

\section{Acknowledgments}


Support from SMARTeR (ESF 2007-09, MICINN BIA2006-27041-E) and MICINN (MAT2009-08654) Projects is gratefully acknowledged. Thanks are also given to the referees for their suggestions to improve the paper.

\section{References}

1. K. Otsuka and C.M. Wayman, Shape Memory Materials, Cambridge University Press, Cambridge, 1998

2. A. Isalgue, C. Auguet, G. Carreras, and V. Torra, SMA (Cu-Based, NiTi) for Use in Damping: The Implications of Reliability for Long Time Applications and Aging Behaviour, Funct. Mater. Lett., 2012, 5(1), p 1250008. doi:10.1142/S1793604712500087

3. V. Torra, A. Isalgue, F. Martorell, P. Terriault, and F.C. Lovey, Built in Dampers for Family Homes via SMA: An ANSYS Computation Scheme Based on Mesoscopic and Microscopic Experimental Analyses, Eng. Struct., 2007, 29, p 1889-1902

4. V. Torra, A. Isalgue, C. Auguet, C. Carreras, F.C. Lovey, and P. Terriault, Damping in Civil Engineering Using SMA Part 2-Particular Properties of NiTi for Damping of Stayed Cables in Bridges, Can. Metall. Q., 2013, 52(1), p 81-89

5. A. Isalgue, V. Torra, F. Casciati, and S. Casciati, NiTi Wires for Dampers and Actuators: Fatigue, European Association Control of Structures June, 2012 (Genoa), 2012

6. V. Torra, A. Isalgue, C. Auguet, G. Carreras, F.C. Lovey, H. Soul, and P. Terriault, Damping in Civil Engineering Using SMA: The Fatigue Behavior and Stability of CuAlBe and NiTi Alloys, J. Mater. Eng. Perform., 2009, 18, p 738-745

7. A. Isalgue, V. Torra, F.C. Lovey, and J.L. Pelegrina, Low Temperature Aging Behavior of Transformation Temperatures in Some Cu-based and NiTi SMA, ESOMAT 2009 (Prague), EDP Sciences, 2009. doi:10.1051/esomat/200905012

8. V. Torra, C. Auguet, A. Isalgue, G. Carreras, and F.C. Lovey, Metastable Effects on Martensitic Transformation in SMA: Part IX. Static Aging for 
Morphing by Temperature and Stress, J. Therm. Anal. Calorim., 2013, 112, p 777-780. doi:10.1007/s10973-012-2585-y

9. V. Torra, C. Auguet, A. Isalgue, F.C. Lovey, A. Sepulveda, and H. Soul, Metastable Effects on Martensitic Transformation in SMA Part VIII. Temperature Effects on Cycling, J. Therm. Anal. Calorim., 2010, 102, p 671-680. doi:10.1007/s10973-009-0613-3

10. H. Soul, A. Isalgue, A. Yawny, V. Torra, and F.C. Lovey, Pseudoelastic Fatigue of NiTi Wires: Frequency and Size Effects on Damping Capacity, Smart Mater. Struct., 2010, 19, p 085006. doi:10.1088/0964-1726 /19/8/085006

11. S. Miyazaki, K. Mizukoshi, T. Ueki, T. Sakuma, and Y.N. Liu, Fatigue Life of Ti-50 at.\% Ni and Ti-40Ni-10Cu (at.\%) Shape Memory Alloy Wires, Mater. Sci. Eng. A, 1999, 273, p 658-663. doi:10.1016/S0921-5093(99)00344-5

12. A.R. Pelton, Nitinol Fatigue: A Review of Microstructures and Mechanisms, J. Mater. Eng. Perform., 2011, doi:10.1007/s11665-011-9864-9

13. G. Kang, Q. Kan, C. Yu, D. Song, and Y. Liu, Whole-Life Transformation Ratchetting and Fatigue of Super-Elastic NiTi Alloy Under Uniaxial Stress-Controlled Cyclic Loading, Mater. Sci. Eng. A, 2012, 535, p 228-234

14. H. Tobushi, K. Miyamoto, Y. Nishimura, and K. Mitsui, Novel Shape Memory Actuator, J. Theor. Appl. Mech., 2011, 49(3), p 927-943

15. S.W. Robertson, A.R. Pelton, and R.O. Ritchie, Mechanical Fatigue and Fracture of Nitinol, Int. Mater. Rev., 2012, 57(1), p 1-36

16. D.W. Norwich and A. Fasching, A Study of the Effect of Diameter on the Fatigue Properties of NiTi Wire, J. Mater. Eng. Perform., 2009, 18, p $558-562$

17. M.F. Ashby and D.R.H. Jones, Engineering Materials: An Introduction to Their Properties and Applications, Pergamon Press, Oxford, 1980, p 136-137 
18. O.H. Basquin, The Exponential Law of Endurance Tests, Proc. Am.

Soc. Test. Mater., 1910, 10, p 625-630

19. A. Isalgue, C. Auguet, R. Grau, V. Torra, N. Cinca, and J. Fernandez, Behavior of NiTi Wires for Dampers and Actuators in Extreme Conditions.

Proceedings of International Conference on Shape Memory and

Superelastic Technologies 2013, (Prague), 2013, p 396-397 